\title{
Jogos digitais e aprendizagem: um estudo pela perspectiva da teoria histórico-cultural
}

Aletheia Machado de Oliveira aletheiaoliveira@yahoo.com.br 0000-0002-1058-0817

Universidade Estadual Paulista,

Presidente Prudente, São Paulo, Brasil.

\begin{abstract}
RESUMO
O presente artigo tem como objetivo analisar a relação de alguns conceitos-chaves da teoria histórico-cultural com a aprendizagem baseada em jogos digitais. Caracteriza-se como um estudo teórico, elaborado por meio de pesquisa bibliográfica acerca do entendimento do jogo enquanto dimensão lúdica na cultura e na sociedade e da aprendizagem baseada em jogos digitais à luz da perspectiva epistemológica citada anteriormente. Fundamenta-se sua análise nos estudos de Vigotski, Leontiev, Luria, Elkonin. Considera-se os jogos digitais como sendo uma atividade humana, elemento constituinte da cultura, com um sistema de regras explícitas e implícitas, que preenche necessidades, possibilita que as relações sociais sejam construídas e reconstruídas, propicia interação, estimula a descoberta, o interesse, a reflexão, viabiliza a aprendizagem de conceitos científicos e atua nas atividades psíquicas. Nesse contexto, este trabalho tem a intenção de contribuir para as discussões que envolvem jogos digitais e aprendizagem, compreendendo que as principais ideias fundadas e desenvolvidas por essa teoria podem estar interligadas para uma era digital.
\end{abstract}

PALAVRAS-CHAVE: Jogos digitais. Aprendizagem. Teoria Histórico-Cultural. 


\section{INTRODUÇÃO}

Este artigo é fruto de trabalho de Doutorado que tem como tema os jogos digitais e a aprendizagem e fundamenta sua análise na teoria histórico-cultural. A temática jogos digitais permeou minha atuação acadêmica e profissional por meio do Grupo de Estudo: Pesquisa e Práticas Curriculares de Informática. Nesse grupo de estudo, senti necessidade em pesquisar o assunto por perceber a falta de sinergia entre conteúdo/jogos digitais e práticas pedagógicas que ainda seguem na perspectiva instrumental de ensino. $\mathrm{O}$ uso deste elemento tecnológico limita-se apenas em consolidar o que foi aprendido em sala de aula.

A educação mediada pelas tecnologias digitais possibilitou transformações na prática educativa, especialmente com a chegada de elementos tecnológicos que podem potencializar o ensino e a aprendizagem. O livro, a TV, o computador, a Internet, os tablets, os celulares e os jogos digitais podem ser apontados como exemplos desses elementos tecnológicos presentes no mundo contemporâneo e usados com frequência por crianças, adolescentes e adultos. Isto possibilita pensarmos o quanto esses sujeitos, se submetidos a uma educação de qualidade, múltipla e desafiadora, podem desenvolver inúmeras potencialidades de aprendizagem e avançar em seu desenvolvimento.

Atendo-se ao elemento tecnológico "jogos digitais", percebemos que sua presença vem se constituindo em um fenômeno cultural que exige investigações e olhares diferenciados, principalmente na área da educação, indo além do entretenimento e apontando a possibilidade de tê-los como parceiros no processo de aprendizagem (ALVES, 2008).

Logo, devemos construir um sentido diferenciado com o uso dos jogos digitais nos espaços escolares para além de uma educação reduzida a uma concepção de aprendizagem behaviorista que apenas conduzem as aulas, ilustram, animam, "[...] que intencionam apenas mensurar o conteúdo aprendido" (ALVES, 2010, p. 222). Devemos nos preocupar com a construção de conceitos para que os alunos possam aplicar o conhecimento elaborado, sistematizado, científico, de forma crítica e consciente, em seu cotidiano. $\mathrm{O}$ uso dos jogos digitais, nesse processo, pode ser considerado um elemento de interesse dentro da aprendizagem baseada em jogos digitais.

Com base em tais inferências, este estudo tem como objetivo analisar a relação de alguns conceitos-chaves da teoria histórico-cultural com a aprendizagem baseada em jogos digitais. Trata-se de um estudo teórico acerca do entendimento do jogo enquanto dimensão lúdica na cultura e na sociedade e da aprendizagem baseada em jogos digitais à luz da perspectiva epistemológica citada anteriormente. A fonte principal para a realização do estudo foi a revisão sistemática de literatura de autores pertencentes à teoria histórico-cultural e aqueles que discutem o uso dos jogos digitais no processo ensino e aprendizagem.

A Teoria Histórico-Cultural, proposição de uma nova teoria por Vigotski ${ }^{1}$, pretendia suplantar duas tendências antagônicas que se faziam presentes na psicologia soviética: um ramo que via a psicologia como ciência natural, com pressupostos positivistas e que deveria se deter na análise dos acontecimentos psicológicos por meio de técnicas exatas, experimentais, sem interferência externa; e outro ramo que via a psicologia como ciência mental, com pressupostos fenomenológicos e que se ocupava puramente da descrição subjetiva (valores, 
desejos, atitudes, raciocínios abstratos) de tais acontecimentos. Essa nova teoria tinha como propósito explicitar a interdependência entre os fenômenos naturais, humanos e sociais, compreender as relações mantidas pelos seres humanos ao tecerem sua existência social e explicar os processos psicológicos humanos (LURIA, 2006).

Procurando compreender o ser humano como síntese de múltiplas determinações (biológicas, históricas, culturais, sociais), em desenvolvimento (pelas relações sociais e apropriação cultural), em constante interação "coletiva" com outros e com objetos materiais (naturais) e simbólicos (culturais), a obra de Vigotski pode contribuir para alimentar o debate no campo educacional, na medida em que fornece alguns conceitos-chaves que poderão contribuir para o campo educacional e diluir com a rigidez das visões tradicionais e conservadoras da escola. Conceitos-chaves esses que precisam nos remeter para a educação e que não podem ser pensados e analisados individualmente, mas que se relacionam e compõem o todo para a compreensão dos fenômenos humanos e sociais na sua concreticidade, ou seja, em suas múltiplas determinações materiais, históricas e sociais. Vigotski estava preocupado com a construção do ser humano pela via da educação escolar.

Dentre os conceitos-chaves mais relevantes da teoria histórico-cultural, podemos elencar o sujeito humano e suas relações sociais, interação, mediação, desenvolvimento das funções psicológicas superiores, relação entre pensamento e linguagem, aprendizado e desenvolvimento, zona de desenvolvimento potencial, atividade criadora, entre outros.

Em consonância com a perspectiva vigotskiana e por entender que seus estudos podem estar interligados para uma era digital, o artigo segue estruturado da seguinte forma: na seção seguinte à introdução, discutiremos o jogo enquanto dimensão lúdica na cultura e sociedade e o que o diferencia dos meios digitais. Em seguida, na seção 3 , será exposta uma discussão acerca da aprendizagem baseada em jogos digitais. Na penúltima seção, será discutido o uso dos jogos digitais no contexto escolar pela perspectiva da Teoria Histórico-Cultural. Na parte final do artigo, teceremos nossas conclusões.

\section{JOGO: CONEXÃO COM A CULTURA E A SOCIEDADE}

O que é jogo? Que conexões mantêm com a cultura e a sociedade? De acordo com Houaiss e Villar, o termo jogo diz respeito a

\footnotetext{
[1] nome comum a certas atividades cuja natureza ou finalidade é recreativa; diversão, entretenimento; [2] competição física ou mental sujeita a uma regra (jogo de cartas, de xadrez, de tênis); [3] atuação de um jogador; [4] instrumento ou equipamento usado para jogar (HOUAISS; VILLAR, 2010, p.459).
}

Autores como Kishimoto (2011), Caillois (2017), Huizinga (2018) e Ranhel (2009) dizem que definir o termo é uma tarefa complexa em função da pluralidade de significados, ou seja, em função da variedade de fenômenos considerados como jogo, por suas peculiaridades que os aproximam ou distanciam. A fim de romper com o nó desta variedade de significados, Brougére $(1981,1993)$ e Henriot $(1983$, 1989) (apud KISHIMOTO, 2011) apontam que o jogo pode ser visto enquanto fato social, ou seja, assume o sentido que cada sociedade Ihe atribui conforme seus 
valores e modos de vida; um sistema de regras que permite reconhecer uma estrutura sequencial que categoriza seu tipo e enquanto objeto materializado.

Elkonin $(2009$, p. 13) também constata sobre a complexidade em delinear um conceito científico stricto sensu para o termo e diz que "[...] não temos, até hoje, uma delimitação satisfatória dessas atividades e uma explicação, também satisfatória, das diferentes formas de jogo [...]". Contudo, o autor conclui que é por meio da atividade jogo que as relações sociais se constroem e se reconstroem.

Verificamos na obra de Caillois (2017) que o vocábulo jogo, além de apresentar uma variedade de atribuições e significados, como atividade sem pressão, ação, desenvoltura, habilidade, relaxamento, divertimento, regras, também se caracteriza como um importante motor, "[...] para as sociedades, do desenvolvimento das mais altas manifestações de sua cultura e, para o indivíduo, de sua educação moral e de seu progresso intelectual” (CAILLOIS, 2017, p. 09).

Isso demonstra a relevância e a presença do jogo na sociedade e nas situações cotidianas, visto que repercute na cultura e na vida coletiva. $O$ ato de jogar é observado em diversas culturas desde os primórdios civilizatórios. Cada cultura conhece e pratica uma grande variedade de jogos de categorias diferentes, ocasionando mudanças em sua função social, mas não em sua natureza (CAILLOIS, 2017).

$\mathrm{Na}$ antiguidade greco-romana, o jogo era visto como recreação, relaxamento às atividades que demandavam esforço físico ou intelectual. Na Idade Média, era visto como "não sério" por sua conexão aos jogos de azar. A partir do Renascimento, serviu para difundir concepções morais, éticas e conteúdos escolares para a aprendizagem. No período Romântico, aparece como conduta típica e espontânea da criança (KISHIMOTO, 2011).

Ao analisarmos a literatura, constatamos que o jogo foi estudado por vários pesquisadores ${ }^{2}$ de diversas áreas do conhecimento e com perspectivas de análise distintas. Mas, "[...] apesar de suas diferenças, há uma complementariedade entre elas", ao proporcionar contribuições importantes para a discussão referente à dimensão lúdica do jogo nos aspectos culturais, afetivos e cognitivos e sociais (KISHIMOTO, 2002, p. 46).

Sob o enfoque filosófico, trazemos para a nossa discussão as contribuições de Huizinga (2014), primeiro filósofo a embasar um estudo sobre a relação entre jogo e cultura, ao destacar que o jogo é um elemento constituinte da cultura e estudado em uma perspectiva histórica que ultrapassa os limites da atividade física ou biológica. As principais características elencadas pelo autor em relação ao jogo é que ele é livre; desligado de qualquer interesse material com o qual não se pode obter lucro; praticado dentro de certos limites temporais e espaciais; com ordem e regras; e formador de grupos sociais.

Etimologicamente, o autor nos diz que é a língua latina que cobre todo o campo do jogo em uma única palavra - ludus, de ludere. Ludus abrange jogos infantis, a recreação, as competições, as representações litúrgicas e teatrais, jogos de azar. Através de exemplos do elemento lúdico presentes desde as mais remotas civilizações e outras tiradas do século XVIII, Huizinga (2014, p. 06) apresenta aspectos que confirmam a presença do jogo nos processos culturais: na poesia, na música, na dança, na linguagem, na competição, na função judicial, na filosofia e 
no saber, comprovando seu papel e importância como "[...] forma específica de atividade, como forma significante, como função social".

Outro autor que teorizou sobre jogo foi Caillois, em continuidade às discussões propostas por Huizinga. Para ele, o jogo é uma atividade livre (voluntária), delimitada (tempo e espaço), imprevisível (sua direção não pode ser determinada), improdutiva (não gera bens, salvo transferi-los), com regulamentos e normas (sujeita a convenções) e fictícia (ilusória realidade em relação à vida cotidiana). Propõe-se quatro categorias de jogos, buscando reunir suas manifestações diferentes: Agon (baseados em competição), Alea (baseados na sorte), Mimicry (baseados na simulação e representação) e Ilinux (baseados em sensações como agitação, sensação, vertigem, desorientação) (CAILLOIS, 2017, p. 42-67).

Na literatura psicológica, destacamos Elkonin (2009) ao enfocar a importância do jogo para o desenvolvimento do psiquismo e formação da personalidade da criança com idade entre seis e sete anos. Inicialmente, o autor discute as várias acepções que o termo "jogo" possui e diz que, na literatura, encontram-se diversas categorias do termo, como jogo imaginativo, jogo cooperativo, jogo simbólico, jogo de ficção, entre outros, assinalando diferenças teóricas entre os vários autores que os utilizam. Em sua obra, Elkonin trata do jogo protagonizado, característico das crianças do final da idade pré-escolar, cooperativo, de reconstituição de papéis e das interações com os adultos.

Apoiado em estudos soviéticos, principalmente em Vigotski, que foi o que mais se aproximou dos estudos da natureza psicológica do jogo, Elkonin (2009, p. 19) defende que o jogo é uma "[...] atividade em que se reconstroem, sem fins utilitários diretos, as relações sociais". O jogo é de origem social, ou seja, resultado de todo um processo histórico, considerando as relações mantidas entre os adultos e as crianças. Acerca da origem histórica do jogo protagonizado, o autor diz que não é possível determinar com exatidão o seu aparecimento, uma vez que nasce no decorrer do desenvolvimento da sociedade, com a mudança de posição da criança no sistema de relações sociais.

Sendo assim, realiza-se uma análise da relação jogo e desenvolvimento infantil, sendo o papel (funções desempenhadas pelos indivíduos) e a ação (realizadas na atividade do jogo) as unidades fundamentais e indivisíveis da evolução da forma do jogo. A criança atua no jogo com objetos da vida real, com suas emoções, exterioriza-as, reconstruindo as condições materiais e as faz tomar novas formas. $\mathrm{O}$ jogo produz o desenvolvimento do psiquismo e da personalidade da criança na esfera da motivação e de suas necessidades, no desenvolvimento moral, nas relações entre as pessoas, nas regras de conduta (ELKONIN, 2009).

Nunes e Filho (2016) consideram o jogo como atividade humana, com intencionalidades e construção social, objeto da cultura corporal essencial ao processo de desenvolvimento humano, sobretudo no processo educativo, ou seja, o jogo é reconstrução das relações sociais estabelecidas em sua vida cotidiana com outras crianças e com os adultos a sua volta [...]. É nessa atividade de jogar que todos esses processos culturais, materiais e simbólicos, relacionais, repleto de manifestações e expressões humanas, são interiorizados e exteriorizados, num movimento dialético que garante as possibilidades para a construção da consciência da criança (NUNES; VIOTTO FILHO, 2016, p. 22). 
Com isso, percebemos que todos os autores conferem ao jogo como sendo atividade humana, elemento constituinte da cultura, com um sistema de regras explícitas e implícitas, preenche necessidades, possibilita que as relações sociais sejam construídas e reconstruídas, propicia interação, estimula a descoberta, o interesse, a reflexão, viabiliza a aprendizagem de conceitos científicos e atua nas atividades psíquicas. Promove ainda o desenvolvimento das funções psicológicas superiores, além de estar relacionado com o modo de vida e a cultura das sociedades.

Nesse sentido, podemos asseverar que tais características são relevantes, seja qual for o jogo, não-digital ou digital. Porém, o que diferencia os jogos em meios digitais? A concepção de jogos digitais, segundo Santaella e Feitoza (2009, p. 09), engloba jogos desenhados para "[...] suportes tecnológicos eletrônicos ou computacionais". Em relação à terminologia, "jogos eletrônicos" seria a expressão genérica mais adequada e "games", a mais abrangente.

Na história dos jogos digitais, estes se dividem em três categorias, conforme o suporte aplicado: jogos para consoles (gerados para designar aparelhos de videogames e exibidos em monitores de TV); jogos para computador (desenvolvidos para computadores pessoais); e jogos para arcades (máquinas dispostas em estabelecimentos públicos e que requerem algum tipo de moeda para serem jogados e conhecido equivocadamente por fliperama). No que tange aos aspectos técnicos, envolvem programação, roteiro de navegação, design de interface, técnicas de animação, usabilidade, paisagem sonora (SANTAELLA; FEITOZA, 2009).

Telles e Alves (2016, p. 126) entendem o jogo digital como um software projetado para uma ou mais plataformas, em que o jogador tem a possibilidade de interagir com esse software, destacando que "o software, portanto, não é o jogo. O jogo é o que se faz com o software e a partir dele."

Carlos Petry (2016) discute a perspectiva ontológica do jogo analógico ao digital. Os jogos digitais surgiram no contexto da computação e funcionam em sistemas computacionais do tipo computadores pessoais, fliperamas, consoles, dispositivos móveis e tablets. São tidos como novos objetos de uma cultura e uma sociedade caracterizada como pós-moderna e que se apresenta de diversas formas e com múltiplas facetas, desde a oportunidade de entretenimento, capacidade de participar da narrativa e se envolver nela como agente direto e com poderes de intervenção no curso das jogadas, possibilidade de vivenciar situações que não seriam possíveis no mundo real, oportunizar situações de aprendizagem, formar comunidades de usuários ao redor do jogo, em treinamentos e como auxiliares em processos de terapia, até o aprimoramento de habilidades.

Em meio a essas discussões, podemos pensar que todos os elementos marcantes destacados pelos autores em relação aos jogos não-digitais estão direcionados ao contexto dos jogos digitais. Ambos consistem em uma atividade livre, com regras que se formam e se transformam, com conflitos, objetivos e possibilidade de tomada de decisões. Inseridos na cultura, o jogo (tanto digital, como não-digital) em si não altera suas características como liberdade, interatividade, delimitação no tempo e espaço, ficção, sistema de regras, imprevisibilidade, ludicidade, representação, entre outras. O que diferencia é a forma de representá-lo: no jogo não-digital, por objetos concretos, físicos; e no 
jogo digital, por elementos gráficos abstratos, com o uso de recursos computacionais.

\section{JOGOS DIGITAIS E APRENDIZAGEM}

Utilizados por crianças e jovens com intensidade em seu cotidiano, os jogos digitais nos remetem à ideia de que podem também ser empregados no contexto da aprendizagem desses sujeitos, criando oportunidades para planejar, problematizar, contextualizar, elaborar e avaliar hipóteses, analisar o erro e discutir os conteúdos aprendidos em sala de aula de forma mais prazerosa e motivadora e, assim, contribuir para a aprendizagem. De modo geral, segundo os autores Contreras-Espinosa e Eguia-Gómez (2016), a aprendizagem baseada em jogos digitais (digital game-based learning - desde já DGBL) equivale ao uso de jogos para auxiliar o processo de ensino/aprendizagem.

Compartilhando desse mesmo ponto de vista, Prensky $(2012$, p. 208) define a aprendizagem baseada em jogos digitais com "[...] qualquer jogo para o processo de ensino e aprendizagem em um computador ou on-line". Nesse processo, é fundamental que o conteúdo esteja bem harmonizado, o estilo de jogo seja envolvente, o estilo de aprendizagem seja coerente com a proposta do jogo e que o aprendiz interaja com o jogo, podendo ser usado na educação infantil, na educação básica, nas universidades e até no trabalho.

A respeito de seu potencial na utilização da aprendizagem, Petry $(2016$, p. 58) apresenta o estado da arte das pesquisas realizadas na área de jogos digitais e aprendizagem, tanto fora, quanto dentro do Brasil, de cunho quantitativo e qualitativo. Melhoria na capacidade perceptiva e no processamento cognitivo, na capacidade motora e acuidade visual, estímulo a reações mais rápidas, motiva a aprendizagem escolar, desenvolve o pensamento lógico-matemático, ajuda a desenvolver habilidades socioafetivas, são alguns elementos apontados pela autora a respeito dos resultados das pesquisas envolvendo a temática, comprovando que "[...] aprende-se por meio de jogos digitais".

Ao olharmos para as pesquisas que envolvem a temática jogos digitais e aprendizagem, vemos que as discussões têm crescido na busca de uma aplicação consciente no processo ensino/aprendizagem. Além de tornar o aprendizado mais divertido, as crianças têm a possibilidade de aprender conceitos escolares de forma diferente e vivenciar habilidades socioafetivas que podem tornar esse processo mais interessante e significativo. Nesse caminhar, as práticas pedagógicas têm que mudar para atender a essa nova demanda, uma vez que nos deparamos com uma abordagem educacional ainda centrada no que ensinar (currículo), em vez de como aprender, com um método de ensino baseado na exposição e avaliação.

Diante desse panorama, podemos pensar que os jogos digitais podem enriquecer a aprendizagem por perpassar diferentes disciplinas e conteúdos, constituindo-se em objeto interdisciplinar ou transdisciplinar (CARLOS PETRY, 2016). Devemos pensar que se fizermos conexões conscientes entre os conteúdos pedagógicos e os jogos digitais, facilitar-se-á a construção eficiente do conhecimento, visto que este elemento tecnológico é bem próximo do cotidiano dos alunos, motivando-os a aprender. 


\section{JOGOS DIGITAIS PELA PERSPECTIVA DA TEORIA HISTÓRICO-CULTURAL}

A perspectiva epistemológica da Teoria Histórico-Cultural trouxe estudos importantes sobre a relação entre o jogo e o desenvolvimento das crianças, ao estabelecê-lo como atividade principal para a aprendizagem e o desenvolvimento infantil. Nesse sentido, podemos trazer à luz da discussão o uso dos jogos digitais no contexto escolar fundamentado nessa teoria.

Vigotski valorizava a interação do indivíduo com outros e com objetos materiais e simbólicos, construídos pela cultura humana. Criados pelos homens para auxiliá-los em suas ações, possibilita sua transformação e consequentemente do contexto no qual estão inseridos. A produção desse objeto material é acompanhada pela produção do objeto simbólico (cultural) e, nesse processo de produção cultural, desenvolve-se a ciência, a arte, a comunicação social, a transmissão do conhecimento, a troca de ideias, pensamentos e sentimentos - o desenvolvimento humano.

Desse modo, podemos afirmar que essa relação entre apropriação e objetivação dos objetos materiais e simbólicos é que impulsiona o desenvolvimento humano, pela ação prático-teórica dos objetos. Trata-se de um processo que se inicia desde o nascimento e, de forma gradativa, faz com que os seres humanos se desenvolvam. Por isso, os progressos realizados na produção de bens materiais são acompanhados pelo desenvolvimento do conhecimento e da cultura. Temos que ter o direito de apropriar-se, ter acesso, conhecimento daquilo que o mundo construiu - os objetos materiais e simbólicos.

Dentre os objetos culturais presentes no cenário contemporâneo, mencionamos os jogos digitais, utilizados intensamente por crianças e jovens em diversos contextos. Segundo Santaella e Feitoza (2009), os jogos digitais vêm desempenhando papel de destaque na cultura humana, pela grande movimentação financeira no conceito de entretenimento e de educação e como produto cultural, visto segundo diversas perspectivas, enquanto mídia, manifestação de arte, fenômeno estético e de linguagem, ícone da cultura pop.

$\mathrm{Na}$ perspectiva vigotskiana, podemos considerar os jogos digitais como objetos culturais, pois, além de serem instrumentos de criação humana, expressam aspectos sociais e culturais, com olhar atento e crítico para uma apropriação qualitativa destes objetos, a fim de não prejudicar a formação desses sujeitos.

Para a Teoria Histórico-Cultural, o jogo é compreendido como atividade principal no período escolar, exercendo enorme influência no desenvolvimento da criança. Não é uma atividade instintiva e sim produtiva, objetiva, humana, coletiva e cooperativa, realizada por meio de ações orientadas por propósitos e desempenhada pelas crianças quando envolvidas na atividade. $O$ que caracteriza a atividade principal é a relação qualitativa da ação da criança com o jogo, que irá favorecer o seu desenvolvimento, e não a quantidade da mesma ação (LEONTIEV, 2006a).

De acordo com o referido autor, atividades são processos que, na relação do homem com o mundo, satisfazem uma necessidade especial. Correspondem a um objetivo que estimula a criança a executá-la. Uma necessidade é satisfeita quando encontra um objeto, a qual chamamos motivo. $O$ motivo instiga uma atividade. Além disso, a atividade está conectada com as ações, um processo de "[...] base 
psicológica concreta sobre a qual ocorrem mudanças na atividade principal e, consequentemente, as transições de um estágio de desenvolvimento para o outro" (LEONTIEV, 2006a, p. 69).

Sistematizado por Leontiev, o autor define atividade principal como:

[...] aquela em conexão com a qual ocorrem as mais importantes mudanças no desenvolvimento psíquico da criança e dentro da qual se desenvolvem processos psíquicos que preparam o caminho da transição da criança para um novo e mais elevado nível de desenvolvimento (LEONTIEV, 2006b, p, 122).

Nesse sentido, não se pode reduzir o uso de jogos digitais na educação, constituindo-se com uma atividade importante da criança no contexto escolar. Por isso, torna-se importante a escola criar motivos sociais para que a criança sinta a necessidade de aprender, conhecer e se apropriar com qualidade desse objeto cultural, tanto no que se refere à habilidade em manipular esse objeto, quanto em apreender criticamente os conceitos científicos que neles estão incutidos, oportunizando a obtenção de aprendizagens que geram desenvolvimento.

É importante destacar que o uso dos jogos digitais no contexto escolar possibilita às crianças experenciar situações lúdicas, promovendo o conhecimento, a aprendizagem pela prática, o trabalho cooperativo, a reflexão, capacidade de planejamento, atenção, memória, imaginação, pensamento abstrato, raciocínio.

Porém, a construção desse conhecimento advém de uma ação compartilhada que implica um processo de mediação, sendo o professor o elemento mediador das interações das crianças com os objetos culturais (no caso, os jogos digitais). 0 aluno é interativo e essa mediação que o leva ao conhecimento e à construção das funções psicológicas superiores tão importantes para o seu desenvolvimento psíquico, intelectual, afetivo e social.

Mas, para que o professor possa intervir e planejar atividades com o uso dos jogos digitais, é necessário que se conheça o nível efetivo das crianças, ou melhor, interesses, como brincam, informações, opiniões, dúvidas, enfim, de que modo interagem com esse objeto. Este é o ponto de partida: diálogo. Com essas informações, o professor terá a possibilidade de planejar atividades significativas em termos dos objetivos que pretende alcançar.

Vigotski (2007, p. 100), assim, evidencia a importância dos processos de aprendizado por despertar múltiplos processos internos de desenvolvimento: “[...] o aprendizado pressupõe uma natureza social específica e um processo através do qual as crianças penetram na vida intelectual daqueles que as cercam". Desse ponto de vista, o aprendizado é um processo necessário e importante para o desenvolvimento das funções psicológicas superiores. Por isso, contrapôs a três teorias que interpretavam de maneira diferente a relação entre desenvolvimento e aprendizagem.

Inicialmente, a primeira teoria, discute a ideia de que a aprendizagem é um processo paralelo, exterior e o desenvolvimento precede o da aprendizagem. Em seguida, segunda teoria fala-nos que há uma sincronização entre ambos os processos, ou seja, cada etapa da aprendizagem corresponde uma etapa de desenvolvimento. Por fim, terceira teoria procura combinar as duas teorias descritas acima. Expressa suas próprias reflexões tomando como ponto de partida o fato de que devemos considerar as experiências adquiridas fora do contexto escolar pelas crianças, ou seja, 
[...] o fato de que a aprendizagem da criança começa muito antes da aprendizagem escolar. A aprendizagem escolar nunca parte do zero. Toda a aprendizagem da criança na escola tem uma pré-história. [...] Pela sua importância, este processo de aprendizagem, que se produz antes que a criança entre na escola, difere de modo especial do domínio de noções que se adquirem durante o ensino escolar. [...] Aprendizagem e desenvolvimento não entram em contato pela primeira vez na idade escolar, portanto, mas estão ligados entre si desde os primeiros dias de vida da criança (VIGOTSKI, 2006, p. 109-110).

Para Vigostski (2006), desenvolvimento e aprendizagem decorrem da relação entre dois níveis de desenvolvimento. O primeiro, chamado de real ou efetivo, é identificado na capacidade da criança em resolver problemas de forma independente. É o nível de desenvolvimento das funções psicológicas já construídas pelas crianças ao longo da sua vida. O segundo nível, chamado de potencial, remete às funções psicológicas que estão em vias de amadurecimento, que a criança não é capaz de realizar sozinha, mas que poderá a vir realizar com o auxílio de outra pessoa em um nível cognitivo mais elevado. Este nível permite conhecer o potencial das crianças. Dois níveis que se encontram num processo cíclico. Temos, então, o conceito de zona de desenvolvimento proximal. $\mathrm{O}$ autor referido compreende que a criança, ao interagir com outros seres humanos, amplia seu repertório de conhecimento e desenvolve a zona de desenvolvimento proximal.

De acordo com tais pressupostos, o uso de jogos digitais, utilizados mediante a proposta de zona de desenvolvimento proximal, deve, ao mesmo tempo em que ajuda a criança a gerenciar o conteúdo de ensino que está além de seu desenvolvimento real, estimular o desenvolvimento cognitivo, criando, por meio de atividades significativas e interligadas ao conteúdo, novas zonas de desenvolvimento proximal. Com isso, o professor ganha papel de destaque na atuação sobre a zona de desenvolvimento proximal e o uso dos jogos digitais. 0 professor é o responsável pela socialização desse objeto cultural em sala de aula e formação humana dessas crianças. Assim, o ato de ensinar e aprender volta-se para as potencialidades das crianças - entre elas, a atividade criadora.

Por atividade criadora, Vigotski (2003a, p. 07) compreende como toda realização humana responsável pela criação de algo novo, quer corresponda aos reflexos de um objeto do mundo exterior, quer seja por determinadas construção do cérebro ou do sentimento que vivem e se manifestam no ser humano. Sendo assim, de acordo com o autor referido, é possível detectar no ser humano dois tipos de atividade, a saber: a reprodutora ou reprodutória, que está ligada à memória e apresenta como essência a repetição de normas de conduta já criadas pelo homem ou relembrar impressões antigas; e a criadora, que é capaz de criar novas concepções e normas a partir das experiências passadas, tornando o ser humano um ente projetado para o futuro com a possibilidade de criar e modificar o seu presente.

Nessa perspectiva, Vigotski (2003a) considera que o ser humano possui a capacidade criadora de forma consciente e orientada, sendo que a imaginação está intimamente relacionada à atividade criadora. Como a atividade criadora pode ser pensada como tudo o que nos rodeia e foi criada pelo homem, ou seja, toda a cultura através da criação artística, científica e técnica, o referido autor destaca que a atividade criadora não deve ser pensada apenas quando grandes intelectuais criam algo relevante para a humanidade e se torna um acontecimento histórico, 
mas também pensarmos nas criações simples que são significativas para o desenvolvimento da nossa sociedade.

Cabe, então, pensarmos que o processo de criação pode ser observado desde a infância, de forma gradual (do simples ao complexo), e vai adquirindo manifestação própria, mantendo-se ligado às nossas experiências vivenciadas, graças à sua ação sobre o mundo mediada por instrumentos e signos.

Para compreender melhor como essa atividade criadora está ligada à realidade, Vigotski destaca quatro formas fundamentais dessa vinculação que permitirá olharmos a imaginação como uma função psíquica vital para esse processo, porque dela se relacionam todas as outras funções psicológicas humanas, como pensamento, linguagem, sentimentos, entre outras.

A primeira vinculação está no fato de toda a imaginação se compor de elementos extraídos da experiência anterior, ou seja, da variedade de experiências que foram acumuladas pelo homem. A segunda vinculação é pautada por experiências sociais, sendo necessário termos experiências acumuladas para termos a possibilidade de ultrapassar o que já foi estudado e realizado a fim de avançarmos nos processos imaginativos. Na terceira vinculação, Vigotski fala sobre o quanto o fator emocional influencia/mobiliza a fantasia, podendo esta influência ser explícita ou implícita. Por fim, a quarta vinculação está ligada ao surgimento do novo, de algum dispositivo técnico, que, ao se materializar no mundo, ajuda no desenvolvimento e na transformação do homem e da própria realidade, ou seja, aquilo que era imaginação pode se transformar em um produto material e continuar a ajudar no processo de transformação social.

Podemos, então, dizer que os processos imaginativos, processos criativos, fantasias têm relação com as apropriações psíquicas dos símbolos, da linguagem, das palavras e são observados desde a infância. A função imaginativa depende das experiências, das necessidades, dos interesses, dos conhecimentos técnicos, das tradições, em dar forma material aos frutos da imaginação e do meio que nos rodeia. Quanto mais ampla são essas apropriações, mais qualitativa serão os processos imaginativos.

Nesse contexto, a escola é decisiva nesse processo à medida que, no cotidiano escolar, a criança tem a oportunidade de apropriar-se dos saberes e ampliar suas experiências para que essa atividade criadora se solidifique. Para isso, é importante fornecer a elas elementos reais de que disponha em sua experiência para sentir, ver, experimentar, vivenciar. É importante propor situações de aprendizagem desafiadoras e multifacetadas que incentivem o seu desenvolvimento intelectual e criador.

E que elementos seriam esses? Citamos a aplicação de jogos digitais em contextos educacionais como um elemento que não tem só o caráter de diversão, mas podem estruturar aspectos cognitivos, sociais, afetivos e culturais nos alunos. O contato desenvolve o raciocínio lógico, melhora a coordenação motora, a criatividade, promove a capacidade de solucionar problemas e a visão estratégica, fortalece a atenção, amplia as habilidades sensoriomotoras, amplifica a busca de respostas aos desafios propostos (ALVES, 2008). 
Portanto, é preciso que os métodos pedagógicos permitam que as crianças criem, expressem, vivenciem, produzem e não somente observem para reter o que está sendo ensinado; um trabalho pedagógico que vá além da dimensão instrucional e reprodutora do conhecimento para uma dimensão que reconheça as potencialidades das crianças.

\section{PARA CONCLUIR}

A Teoria Histórico-Cultural trouxe para o campo educacional conceitos-chaves importantes a serem discutidos em ações que envolvam o aprendizado e o desenvolvimento das crianças em idade escolar. A reflexão teórica proposta no artigo demonstra que precisamos criar condições reais, concretas, significativas, de conhecimento, a partir do contato com objetos culturais criados pelo homem. Oferecer à criança contato com objetos culturais, apresentar e explicar a relação com o conteúdo que está sendo trabalhado em sala de aula, possibilita pensarmos o quanto as crianças, se submetidas a uma educação de qualidade, múltipla, desafiadora, poderão desenvolver inúmeras potencialidades e avançar em seu desenvolvimento.

A utilização dos jogos digitais na aprendizagem pode ser considerada uma estratégia interessante por estar próxima do cotidiano das crianças. Para serem aplicados em sala de aula, devemos fazer uma análise técnica e pedagógica desses objetos culturais para que a aprendizagem aconteça. Uma boa aprendizagem é aquela que avança, se adianta ao desenvolvimento.

As possibilidades de uso dos jogos digitais na aprendizagem evidenciam que é possível aprender por meio desses objetos culturais. A aprendizagem torna-se mais dinâmica e interativa e a oportunidade de apropriar-se destes elementos tecnológicos ajudará as crianças a desenvolver aspectos cognitivos, sociais, afetivos e culturais. Nesse sentido, compreendemos que os estudos da teoria histórico-cultural podem estar interligados para uma era digital com o uso dos jogos digitais nesse processo de ensino/aprendizagem. 


\title{
DIGITAL GAMES AND LEARNING: A STUDY FROM THE PERSPECTIVE OF HISTORICAL- CULTURAL THEORY
}

\begin{abstract}
This article aims to analyze the relationship of some key concepts of historical-cultural theory with learning based on digital games. It is characterized as a theoretical study, elaborated through bibliographic research about the understanding of the game as a playful dimension in culture and society and of learning based on digital games in the light of the epistemological perspective mentioned above. Its analysis is based on the studies of Vigotski, Leontiev, Luria, Elkonin. Digital games are considered to be a human activity, a constituent element of culture, with a system of explicit and implicit rules, which fills needs, allows social relationships to be built and reconstructed, provides interaction, stimulates discovery, interest, reflection, enables the learning of scientific concepts and acts in psychic activities. In this context, this work intends to contribute to the discussions involving digital games and learning, understanding that the main ideals founded and developed by this theory can be interconnected for a digital age.
\end{abstract}

KEYWORDS: Games. Learning. Historical-Cultural Theory. 


\section{NOTAS}

1 Optamos pela grafia Vigotski, em função do seu nome aparecer escrito conforme obras consultadas.

2 Maiores informações sobre o estudo dos jogos por pesquisadores de diversas áreas do conhecimento encontram-se nas páginas 07-11, do livro 0 jogo e a Educação Infantil, da autora Kishimoto (2002).

3 "Cuanto más vea, oiga y experimente, cuanto más aprenda y assimile, cuantos más elementos reales disponga em su experiência, tanto más considerable y productiva será, a igualdad de las restantes circunstancias, la atividade de su imaginación".

\section{REFERÊNCIAS}

ALVES, L. Jogos, Educação e História: novas possibilidades para a Geração C. Plurais Revista Multidisciplinar, Salvador, v. 1, n. 2, p. 209-225, 2010. Disponível em: https://www.revistas.uneb.br/index.php/plurais/article/view/877. Acesso em: 28 abr. 2019.

Relações entre jogos digitais e aprendizagem: delineando percurso.

Revista Educação, Formação e Tecnologias, EDUCOM, v. 1, n. 2, p. 03-10, 2008. Disponível em: http://eft.educom.pt/index.php/eft/article/view/58. Acesso em: 27 abr. 2019.

CAILLOIS, R. Os jogos e os homens: a máscara e a vertigem. Petrópolis: Editora Vozes, 2017.

PETRY, L. C. O conceito ontológico de jogo. In: ALVES, L.; COUTINHO, I. J. (orgs.). Jogos digitais e aprendizagem: fundamentos para uma prática baseada em evidências. Campinas, SP: Papirus, 2016. p. 17-42.

CONTRERAS-ESPINOSA, R. S.; EGUIA-GÓMEZ, J. L. Pesquisa da avaliação e da eficácia da aprendizagem baseada em jogos digitais: reflexões em torno da literatura científica. In: ALVES, L.; COUTINHO, I. J. (orgs.). Jogos digitais e aprendizagem: fundamentos para uma prática baseada em evidências. Campinas: Papirus, 2016. p. 61-76.

ELKONIN, D. B. Psicologia do jogo. 2 ed. São Paulo: Editora WMF Martins Fontes, 2009.

HOUAISS, A.; VILLAR, M. S. Jogo. In: HOUAISS, A.; VILLAR, M. S. Jogo. Dicionário Houaiss da Língua Portuguesa. 4 ed. Rio de Janeiro: Objetiva, 2010. p. 459. 
HUIZINGA, J. Homo ludens: o jogo como elemento da cultura. 8 ed. São Paulo: Perspectiva, 2018.

KISHIMOTO, T. M. O jogo e a educação infantil. 3 ed. São Paulo: Pioneira Thomson Learning, 2002.

KISHIMOTO, T. M. Jogo, brinquedo, brincadeira e a educação. 14 ed. São Paulo: Cortez, 2011.

LEONTIEV, A. N. Uma contribuição à teoria do desenvolvimento da psique infantil. In: VIGOTSKI, L. S.; LURIA, A. R.; LEONTIEV, A. N. Linguagem, desenvolvimento e aprendizagem. 10 ed. São Paulo: Ícone, 2006a. p. 59-83.

Os princípios psicológicos da brincadeira pré-escolar. In: VIGOTSKI, L. S.; LURIA, A. R.; LEONTIEV, A. N. Linguagem, desenvolvimento e aprendizagem. 10 ed. São Paulo: Ícone, 2006b. p. 119-142.

LURIA, A. R.; VIGOTSKII, L. S. In: VIGOTSKI, L. S.; LURIA, A. R.; LEONTIEV, A. N. Linguagem, desenvolvimento e aprendizagem. 10 ed. São Paulo: Ícone, 2006. p. 21-37.

NUNES, R. L.; FILHO, I. A. T. V. A atividade do jogo e suas implicações para o desenvolvimento da consciência da criança na escola. Curitiba: CRV, 2016.

PETRY, A. S. Jogos digitais e aprendizagem: algumas evidências em pesquisa. In: ALVES, L.; COUTINHO, I. J. (orgs.). Jogos digitais e aprendizagem: fundamentos para uma prática baseada em evidências. Campinas, SP: Papirus, 2016. p. 43-60.

PRENSKY, M. Aprendizagem baseada em jogos digitais. São Paulo: Editora Senac. São Paulo, 2012.

RANHEL, J. O conceito de jogo e os jogos computacionais. In: SANTAELLA, L.; FEITOZA, M. (orgs.). Mapa do jogo: a diversidade cultural dos games. São Paulo: Cengage Learning, 2009. p. 03-22.

SANTAELLA, L.; FEITOZA, M. (orgs.). Mapa do jogo: a diversidade cultural dos games. São Paulo: Cengage Learning, 2009.

TELLES, H. V.; ALVES, L. Ensino de História e Videogame: problematizando a avaliação de jogos baseados em representações do passado. In: ALVES, L.; COUTINHO, I. J. (orgs.). Jogos digitais e aprendizagem: fundamentos para uma prática baseada em evidências. Campinas, SP: Papirus, 2016. p. 125-162. 
VIGOTSKI, L. S. A formação social da mente: o desenvolvimento dos processos psicológicos superiores. 7 ed. São Paulo: Martins Fontes, 2007.

Aprendizagem e desenvolvimento intelectual na idade escolar. In: VIGOTSKI, L. S.; LURIA, A. R.; LEONTIEV, A. N. Linguagem, desenvolvimento e aprendizagem. 10 ed. São Paulo: Ícone, 2006. p. 103-117.

Arte e Imaginacion. In: VIGOTSKI, L. S. La imaginación y el arte em la infância. 6. ed. Madri: Ediciones Akal, 2003a. p. 07-13.

Imaginacion y Realidad. In: VIGOTSKI, L. S.; La imaginación y el arte em la infância. 6. ed. Madri: Ediciones Akal, 2003b. p. 15-29.

Recebido: 30 jul. 2019.

Aprovado: 06 mai. 2020.

DOI: $10.3895 /$ rbect.v13n3.10420

Como citar: OLIVEIRA, A. M. Jogos digitais e aprendizagem: um estudo pela perspectiva da teoria históricocultural. Revista Brasileira de Ensino de Ciência e Tecnologia, Ponta Grossa, v.13, n. 3, p. 186-201, set./dez. 2020. Disponível em: <https://periodicos.utfpr.edu.br/rbect/article/view/10420>. Acesso em: XXX. Correspondência: Aletheia Machado de Oliveira - aletheiaoliveira@yahoo.com.br

Direito autoral: Este artigo está licenciado sob os termos da Licença Creative Commons-Atribuição 4.0 Internacional. 